\title{
PESQUISADORES BANIWAS: DOMESTICANDO OS CONHECIMENTOS E A TECNOLOGIA DO BRANCO
}

\author{
DIEGO SOARES DA SILVEIRA ${ }^{1}$ \\ $U F U, B R A S I L$
}

\begin{abstract}
RESUMO: Neste artigo, apresento reflexões a partir de uma etnografia realizada em redes sociotécnicas formadas em torno de duas pesquisas que contaram com a participação diretaenquanto pesquisadores indígenas - de jovens da etnia Baniwa, visando o estabelecimento de um diálogo entre a perspectiva dos cientistas e o conhecimento indígena. Tal participação também surge como uma demanda das lideranças indígenas, em um contexto de problematização das relações entre pesquisadores e comunidades da região do Alto Rio Negro. Essa problematização das relações intercientíficas se insere em uma conjuntura histórica mais ampla, que teve início com a promulgação da Convenção sobre Diversidade Biológica, na década de 1990, e a instauração de novos princípios jurídico-governamentais no que se refere ao chamado acesso aos conhecimentos tradicionais associados à biodiversidade. Busca-se analisar a perspectiva baniwa sobre o papel de mediação exercido por esses jovens na relação com os pesquisadores brancos, de modo a destacar a forma como esse movimento se insere em uma economia da alteridade formulada em torno dos conceitos de predação e domesticação de saberes, mercadorias e tecnologias, algo já descrito na literatura etnológica como devir-branco.
\end{abstract}

Palavras-Chaves: Relações Intercientíficas; Economia da Predação Ameríndia; Baniwa.

\begin{abstract}
In this article, I present reflections based on an ethnography carried out in sociotechnical networks formed around two researches that had the direct participation - as indigenous researchers - of Baniwa young people, aiming to establish a dialogue between the perspective of scientists and the indigenous knowledge. Such participation also emerges as a demand of the indigenous leaderships, in a context of problematization of the relations between researchers and communities in the Alto Rio Negro region. This problematization of interscientific relations is part of a broader historical context, which began with the promulgation of the Convention on Biological Diversity in the 1990s and the establishment of new legal and governmental principles regarding the so-called access to traditional knowledge associated with biodiversity. The aim is to analyze the Baniwa perspective on the role of mediation exercised by these young people in the relationship with white researchers, in order to highlight the way in which this movement is inserted in an economy of alterity formulated around the concepts of predation and domestication of knowledge, commodities and technologies, already described in the ethnological literature as the process of becoming-white.
\end{abstract}

Keywords: Inter-Scientific Relations; Amerindian Economy of Predation; Baniwa.

\footnotetext{
${ }^{1}$ Professor Adjunto IV do Instituto de Ciências Sociais e Coordenador do Programa de Pós-Graduação em Ciências Sociais (Universidade Federal de Uberlândia, Brasil). E-mail: soares2br@yahoo.com.br.
} 


\section{Introdução}

As reflexões apresentadas aqui resultam de uma etnografia de redes sociotécnicas formadas em torno de dois projetos desenvolvidos pela Organização Não-Governamental "Instituto Socioambiental" (ISA), em parceria com a "Federação das Organizações Indígenas do Rio Negro" (FOIRN), na região noroeste da Amazônia: Agrobiodiversidade nas Terras Indígenas do Alto Rio Negro e Paisagens Baniwa do Içana. Essas pesquisas envolveram o acesso aos conhecimentos tradicionais associados à biodiversidade, tendo sido autorizadas pelo governo brasileiro no início do século XXI, colocando-se em uma perspectiva de "diálogo" com as práticas de conhecimento indígenas. Neste caso, vamos analisar um aspecto fundamental dessas duas iniciativas e que as diferenciam de outras frentes de pesquisas na Amazônia: a participação de pesquisadores indígenas na equipe do projeto.

Esses pesquisadores nativos passaram por um processo de formação e trabalharam diretamente nas etapas de coleta e sistematização de dados. A realização dos projetos a partir de uma parceria entre pesquisadores brancos e indígenas faz parte de um conjunto mais amplo de iniciativas - todas realizadas a partir da rede ISA/FOIRN - que começou a se multiplicar na região do Alto Rio Negro nos últimos vinte anos. O I Seminário de Pesquisa no Rio Negro, realizado no ano 2000 em São Gabriel da Cachoeira (AM), reuniu pesquisadores e comunidades na revisão crítica das relações intercientíficas na região. Entre as diretrizes concebidas nesse encontro, estava a sugestão de inclusão de pesquisadores indígenas nas equipes dos projetos.

Ao discutir a questão com lideranças da FOIRN, em 2010, tive a nítida impressão de que a participação de pesquisadores indígenas nos projetos visava o estabelecimento de algum tipo de controle social sobre o pesquisador branco. $\mathrm{O}$ aspecto da troca de conhecimentos entre brancos e índios também era enfatizado, com atenção especial ao aprendizado que esses jovens vivenciavam ao participar dessas iniciativas. O tema dos pesquisadores indígenas foi associado, na fala das lideranças, a outras demandas políticas, como a formação de assessores indígenas, a luta pela instituição de uma Universidade Indígena e a busca de uma maior autonomia política para as associações indígenas.

Neste artigo, pretendo discutir o conceito de mediação tendo em vista a perspectiva das lideranças e dos próprios pesquisadores indígenas. Ao acompanhar esses jovens e ouvir suas reflexões sobre o engajamento nas pesquisas, tive a nítida impressão de que, apesar deles concordarem sobre a ideia do "trânsito" entre a equipe e a comunidade, a forma como entendem esse deslocamento é diferente. Neste caso, a mediação é pensada como um deslocamento entre duas naturezasculturas envolvendo, mais do que o domínio de duas linguagens (epistemologias), um processo de metamorfose corporal que implica a adoção de novas habilidades, disposições e afecções. 
Antes de desenvolver essas reflexões sobre mediação, no entanto, gostaria de mostrar que estamos diante de uma categoria heterogênea, pois existem múltiplas formas de ser pesquisador indígena. Apesar da institucionalização dessa categoria ser recente, o envolvimento de índios com atividades de pesquisa e projetos de desenvolvimento sustentável já vem ocorrendo há um bom tempo. Para isso, tomarei a trajetória de três pesquisadores baniwas como exemplo de diferentes transformações dessa categoria na região do Alto Rio Negro. Cada uma dessas trajetórias exemplifica três gerações sucessivas de pesquisadores indígenas, fornecendo um panorama geral sobre a emergência dessa categoria. Veremos como o envolvimento dos baniwas com a pesquisa vem ocorrendo de diferentes formas, todas inseridas no panorama histórico mais amplo do contato com o branco.

Após apresentar algumas reflexões iniciais sobre o envolvimento dos índios com a pesquisa, pretendo aprofundá-las ao final do artigo a partir de um diálogo com estudos etnológicos que buscam iluminar a perspectiva indígena sobre o contato, descrevendo as estratégias que os índios mobilizam para lidar (e domesticar) a alteridade do branco, suas mercadorias e conhecimentos.

\section{Pesquisadores baniwas no Alto Rio Negro: diferentes trajetórias e gerações}

\section{Transformação I - de liderança indígena a pesquisador}

No projeto Paisagens Baniwa, havia um coordenador indígena da equipe de pesquisadores nativos, função desempenhada por A. B., baniwa do clã Waliperedakenai, que nasceu, em 1973, na comunidade de Tucumã-rupitá (Médio Içana), onde vivia até o final desta pesquisa. Em 1983, A. B., então com dez anos de idade, começou a primeira série do ensino fundamental na Escola Portas Abertas, localizada na comunidade de Jandu Cachoeira. Para se deslocar até a escola, tinha que acordar de madrugada e fazer um percurso de quatro horas em uma canoa a remo. Mesmo assim, os pais fizeram questão que ele e os irmãos estudassem. Foi desta forma que aprendeu a fazer contas e a falar, ler e escrever em língua portuguesa. Após completar a $4^{\mathrm{a}}$ série, A. B. e os irmãos foram enviados para estudar na Escola Agrícola Rainha dos Apóstolos, em Manaus, mas não se adaptaram à vida na cidade.

Em 1988, ele fez uma viagem para a Colômbia e Venezuela com o avô, quando vivenciou a primeira experiência de trabalho na coleta de piaçaba (Attalia funifera). Depois disso, seguiu-se uma sequencia de períodos intercalados entre a sua comunidade no Içana e viagens para a Colômbia com parentes para trabalhar. Segundo ele, esses momentos de engajamento familiar em atividades de coleta visavam viabilizar o acesso às mercadorias ocidentais (compradas nas cidades ou nos regatões): roupas, calçados, terçados, utensílios domésticos (panelas, baldes e recipientes de plástico), sal, óleo e fósforos. Seus pais conheceram esses 
produtos através da relação com comerciantes brancos, missionários salesianos e, mais tarde, com os evangélicos.

Já no início da década de 1990, A. B. fez um curso de capacitação no magistério e trabalhou como professor de ensino fundamental nas comunidades de Tucumã, São José e Tunuí Cachoeira. Durante esse período, ajudou a fundar a "Organização Indígena da Bacia do Içana" (OIBI) e, em 1992, participou da primeira assembleia. Dois anos depois, foi eleito pela primeira vez como secretário, cargo que ocupou até o ano 2000 , quando passou a desempenhar a função de tesoureiro. Assim como ele, os seus irmãos são lideranças indígenas baniwa. $O$ envolvimento deles com o movimento indígena é marcado pela fundação da associação e a parceria com funcionários e pesquisadores do ISA. No decorrer da década de 1990, A. B. atuou em várias iniciativas de desenvolvimento sustentável, como os projetos na área de piscicultura e artesanato indígena. Nesse contexto, experimentou na prática os múltiplos conhecimentos necessários para administrar recursos e projetos, além de viver o cotidiano institucional do movimento indígena. Ele também manteve uma relação próxima com os parentes durante todo esse tempo, mantendo roça e casa na comunidade.

A trajetória retratada possui aspectos em comum com a experiência de outros líderes indígenas da mesma geração, que viveram intensamente $o$ processo de reconhecimento de suas terras e participaram, no decorrer da década de 1990, da fundação de organizações indígenas na região. Conforme será retomado ao final deste artigo, o envolvimento em projetos e iniciativas levadas adiante no âmbito da rede ISA/FOIRN está diretamente associado às experiências anteriores com o mundo do branco: num primeiro momento, a luta para finalizar os estudos, resultado do engajamento dos pais em garantir aos filhos "um futuro melhor"; mais tarde, as viagens de trabalho na companhia dos familiares, motivadas principalmente pela necessidade de adquirir mercadorias como fósforo, óleo, vela, gasolina, etc. Essas experiências iniciais no mundo do branco - tanto no contexto da escola como do trabalho - foram fundamentais para o engajamento posterior na formação das associações e no movimento indígena organizado, o que exigiu um domínio mínimo do português e de outros conhecimentos adquiridos a partir da convivência com os educadores, comerciantes e patrões.

Em certo sentido, a trajetória de A.B. pode ser entendida como um movimento em direção ao mundo do branco, marcado principalmente pela tentativa de domesticação de conhecimentos e mercadorias. Esse movimento foi vivenciado com outros baniwas de sua geração, em um período histórico marcado por um intenso contato com comerciantes, patrões e missionários. Foi nesse contexto que se deu a sua conversão à religião protestante, que o levou a abandonar certos aspectos da vida cerimonial condenados pelos pastores. Quando olhamos para esse período de forma isolada, somos levados a ver os índios como vítimas de forças exógenas e coloniais. Mas quando deslocamos o foco da análise, percebemos que essas experiências na escola, na igreja e no mundo do trabalho possibilitaram a captura dos aparelhos ocidentais (saberes, técnicas e objetos) agenciados no contexto mais recente dos projetos e 
associações. Foi através dessas experiências que os baniwas aprenderam a lidar com a alteridade do branco, adquirindo e incorporando conhecimentos práticos como a língua portuguesa, a postura corporal e outros detalhes importantes para conduzir a interação de forma favorável aos seus interesses. Esses saberes práticos, múltiplos e microscópicos foram agenciados na fundação da OIBI, na organização e condução das assembleias e, mais recentemente, na execução de atividades de geração de renda para as comunidades do Içana.

Esse movimento de captura dos conhecimentos e objetos do branco teve continuidade através do engajamento dos baniwas nas pesquisas, em que tiveram a oportunidade de aprender com os pesquisadores a fazer anotações, aplicar questionários e entrevistas, desenhar mapas, identificar e coletar plantas na mata, operar aparelhos de GPS e outros tantos procedimentos. Isso lhes permitiu adquirir - no sentido de acoplar ao corpo - os aparelhos que constituem a corporalidade dos pesquisadores. Quando questionado sobre o interesse em aprender a manipular esses equipamentos, A. B. contou que ao percorrer as trilhas na companhia dos parceiros brancos, "registrando" e "coletando" plantas, tirando fotografias e anotando tudo em um caderno, descobriu "coisas que não via antes, apesar de já ter andado por todos esses lugares". Ele deu o exemplo das pesquisas na área de piscicultura: "a visão que a comunidade tem do peixe é a visão do pescador, que está ali todo dia, esperando para pegar a sua comida. Já o pesquisador vai lá e anota tudo: quantos peixes, o tamanho, o tipo e tudo isso aí".

Atualmente, A. B. é considerado um pesquisador experiente, principalmente por já ter participado de vários projetos e ter um histórico bastante amplo de convivência com os brancos. Antes de atuar no projeto sobre paisagens, integrou como pesquisador indígena o projeto Arumã, quando conheceu os pesquisadores do "Instituto Nacional de Pesquisa da Amazônia" (INPA) e do Instituto Socioambiental, aprendeu a fazer coleta botânica e entrevistas. No projeto sobre paisagens florestais, além de ajudar a coordenar as atividades de coleta de dados desempenhadas pelos pesquisadores baniwas em suas comunidades, no Içana, ele teve um papel fundamental no processo de consentimento informado para a realização da pesquisa. Atualmente, está trabalhando em projetos sobre piscicultura e produção de pimenta, em que orienta o trabalho "dos seus pesquisadores", conforme ele se refere aos jovens baniwas que estão sob sua supervisão.

\section{Transformação II - de pesquisador indígena à liderança comunitária}

M. S. é baniwa, nascido em 1980 na comunidade de Camarão, no rio Aiari, um afluente do Uaupés, próximo da fronteira com a Colômbia. Em 1983, sua família iniciou um lento processo de migração para São Gabriel da Cachoeira. Primeiro, com viagens de quatro em quatro meses para receber a aposentadoria do avô. Depois, em viagens com os pais para vender farinha e adquirir mercadorias como sal, óleo, fósforo, terçado, roupas, calçados, gasolina para o motor de polpa e utensílios 
domésticos. Em 1985, foram convidados por um parente para tomar conta de um sítio localizado na estrada de Camanaus. No mesmo ano, abriram a primeira roça nas proximidades do aeroporto, em área militar. Para ficarem mais próximos do local de trabalho, acabaram mudando para as margens da pista de pouso. No final do ano, resolveram retornar ao Aiari para buscar suas coisas. Dois anos mais tarde, a FUNAI passou a pressioná-los para que se retirassem do local, considerado perigoso e inadequado para moradia. Após inúmeras negociações, conseguiram um terreno nas margens da estrada que dá acesso ao aeroporto, próximo das roças e distante da pista de pouso, onde se estabeleceram definitivamente e formaram a comunidade Itacoatiara Mirim. Aos poucos foram chegando outras famílias, inclusive de outras etnias; em 2011, cerca de 100 pessoas viviam na comunidade.

Até os dez anos de idade, M. S. ajudava a mãe na roça e acompanhava o pai em rápidas visitas à cidade. Em 1990, começou a frequentar a escola São José, na comunidade Tapajós. Quatro anos depois, completou a $4^{\mathrm{a}}$ série do ensino fundamental e foi transferido para uma escola no centro da cidade, onde cursou até a $7^{a}$ série. Em 1997, quando estava na metade da $8^{a}$ série, abandonou a escola para trabalhar na coleta de piaçaba. Segundo ele, porque queria comprar roupas, tênis e ter dinheiro para sair à noite, pois seus pais não tinham condições para Ihe dar essas coisas. Nos anos seguintes, voltou a estudar e passou a alternar o tempo entre a escola e as atividades de trabalho. Foi nesse período que começou a beber, afastou-se da comunidade e da família, permanecendo longos períodos na cidade, em casas de amigos e colegas. Segundo seu pai, a "salvação" do filho teve inicio com o ingresso na pesquisa sobre Arumã (ISA/FOIRN), planta usada na confecção do artesanato baniwa. Entre os anos 2000 e 2003, M. S. auxiliou os pesquisadores do INPA no levantamento de dados nas comunidades baniwa do Içana. Foi quando "aprendeu a fazer pesquisa", tendo o primeiro contato com o uso de instrumentos como GPS, mapas e questionários.

Em outubro de 2003, M. S. ingressou como pesquisador indígena em um projeto sobre a produção e uso de adubo orgânico feito a partir da casca da maniva, conduzido por um professor da Escola Agrotécnica. Desta vez, ganhou uma bolsa de sessenta reais para visitar as roças da comunidade e aplicar questionários. Em 2005, foi convidado para ingressar na equipe de pesquisadores do projeto sobre agrobiodiversidade. Até 2007, quando M. S. deixou a equipe para visitar um parente na Venezuela, participou de várias oficinas e reuniões de capacitação em técnicas de pesquisa, tendo atuado na coleta de dados nas comunidades, quando visitou roças e "registrou conhecimentos sobre as plantas".

Nos últimos anos, M. S. usou seus conhecimentos do mundo do branco para fazer todos os procedimentos burocráticos necessários para fundar uma associação comunitária, além de ter auxiliado o coordenador da pesquisa Paisagens Baniwa na elaboração de um projeto que recebeu financiamento da Petrobrás: um documentário retratando a viagem da família até a sua antiga comunidade no rio Aiari com o objetivo de 
resgatar as flautas sagradas, que ainda se encontravam escondidas em um igarapé da região. Além disso, ele continua acompanhando pesquisadores brancos (como eu) em suas atividades de pesquisa.

$\mathrm{O}$ caso de M. S. é um pouco diferente de A. B., tanto pelo fato dele ser de uma geração mais nova e viver em uma comunidade "urbana" localizada a alguns quilômetros do centro de São Gabriel, como, e principalmente, porque neste caso o engajamento no universo da pesquisa forneceu a esse jovem os instrumentos necessários para a formação de uma associação indígena em sua comunidade. Estamos diante de uma transformação simetricamente inversa à anterior: se em um primeiro momento são as lideranças baniwas que se tornam pesquisadores, num segundo momento são os pesquisadores baniwas que se tornam lideranças comunitárias. Nota-se, de qualquer forma, que as incursões no mundo da escola e em empregos eventuais no ramo da construção civil foram importantes posteriormente, facilitando a inserção no meio dos projetos e pesquisadores. Conforme M. S. mencionou algumas vezes, foi na escola e no trabalho que aprendeu a se relacionar com os brancos, a falar melhor o português e a fazer contas. De qualquer forma, o seu relato aponta que essa experiência com o mundo do branco também pode ser prejudicial: com o dinheiro adquirido na construção civil, M. S. começou a beber e se afastou da comunidade e da família. O ingresso na pesquisa ofereceu-lhe a possibilidade de fazer esse caminho de uma forma mais segura ou controlada, principalmente, devido à postura mais amistosa dos pesquisadores (em comparação com os patrões da construção civil).

O envolvimento em projetos e iniciativas realizadas no âmbito da rede ISA/FOIRN possibilita o contato com a linguagem dos projetos e com o ambiente das associações indígenas e das ONGs. Essa experiência é agenciada na constituição de associações comunitárias, formadas para traduzir e encaminhar as demandas locais em projetos e recursos. Ao atuar em pesquisas, os baniwas familiarizaram-se com os prazos, cronogramas, orçamentos e procedimentos comuns a esse meio. Ao ver a quantidade de recursos acessados por essas instituições, busca-se envolver as comunidades nessas iniciativas.

Essa transição de pesquisador à liderança comunitária revela um perfil que parece se repetir em outras comunidades do Alto Rio Negro, tendo em vista que os primeiros jovens envolvidos diretamente em atividades de pesquisa - seja nas escolas indígenas ou em projetos fizeram uso dos conhecimentos adquiridos nesse contexto para fortalecer e apoiar o trabalho desenvolvido no âmbito das organizações indígenas. Esse movimento, no entanto, também implica a emergência dos mesmos conflitos que afligem as lideranças indígenas, conforme já foi apontado nos trabalhos de Garnelo (2003) e Luciano (2006). O engajamento de M.S. em atividades de pesquisa resultou, muitas vezes, no afastamento da comunidade por dias ou até mesmo semanas, o que não era bem visto pela esposa. Ainda antes de voltar para Brasília, fiquei sabendo que ela havia retornado à comunidade paterna, por já não suportar mais a ausência do marido em casa. 
Esses problemas associados ao exercício das atividades como pesquisador parecem ter se intensificado ainda mais com a transformação de M. S. em liderança indígena. A falta de entendimento sobre os procedimentos burocráticos associados à aprovação dos projetos e à liberação e execução dos recursos motivou a desconfiança de alguns membros da comunidade, que passaram a criticá-lo e a cobrar satisfação sobre recursos que ainda não haviam sido liberados. Ao finalizar a primeira etapa do trabalho de campo, os ânimos na comunidade estavam bem acirrados. Enquanto o pai de M. S. acusava o professor de ter incentivado crianças da comunidade a matar suas galinhas e a roubar certa quantia de dinheiro - que mais tarde foi devolvida pelo pai da criança - o pesquisador, agora transformado em líder comunitário, temia ficar doente devido ao risco de ser alvo de feitiço por parte dos insatisfeitos.

$\mathrm{Na}$ ocasião do meu retorno, alguns meses depois, o quadro tinha mudado bastante: o pai de M. S. havia promovido uma grande festa (pudáli) ao final do ano, acalmando os mais críticos com a distribuição de comida e bebida na comunidade; nesse curto intervalo, M. S. foi eleito agente de saúde indígena e o irmão tornou-se o novo capitão de Itacoatiara Mirim. Com isso, a circulação de boatos que colocavam em dúvida a atuação da família na associação comunitária diminuiu significativamente, assim como os ataques às suas galinhas.

\section{Transformação III - a institucionalização da pesquisa nas escolas indígenas}

J. D. é baniwa do clã Liedawieni, nasceu em 1990, na comunidade de Juivitera, localizada na região do Médio Içana. Com sete anos de idade, ingressou na escola da sua comunidade, onde cursou até a $4^{a}$ série do ensino fundamental. Em 2005, matriculou-se na "Escola Indígena Baniwa e Coripaco EIBC-Pamáali", onde teve o primeiro contato com pesquisa, um dos principais eixos pedagógicos presentes nas iniciativas de ensino intercultural conduzidos na região. No mesmo ano, foi convidado pelo capitão da comunidade a participar como "pesquisador indígena" do projeto Paisagens Baniwa. Durante esse período, J. D. participou de vários eventos de formação: cinco encontros de capacitação em técnicas de pesquisa, um curso de formação em manejo de recursos pesqueiros e uma oficina de cartografia. Nesses eventos, aprendeu a desenhar mapas, fazer coleta e identificação botânica, aplicar entrevistas, usar o GPS e programas de informática. Além disso, conduziu boa parte do trabalho de coleta de dados na sua comunidade sob a orientação dos dois coordenadores do projeto e a partir de um diálogo constante com os "velhos".

A breve trajetória de J. D. reproduz o mesmo padrão encontrado em dezenas de jovens baniwas envolvidos em pesquisas no âmbito da rede ISA/FOIRN. Esse é o caso de outros quatro jovens que também atuaram na pesquisa sobre paisagens baniwa, todos da mesma faixa etária. Atualmente, existem dezenas de iniciativas na área de pesquisa intercultural envolvendo jovens pesquisadores indígenas, que atuam em 
suas comunidades sob a supervisão das lideranças e dos pesquisadores do ISA. Esse trabalho está diretamente associado à institucionalização da pesquisa no currículo das escolas indígenas onde esses jovens estudam e na orientação participativa e intercultural dos projetos na área de desenvolvimento sustentável. O interessante, neste caso, é que esses jovens acabam conhecendo aspectos da própria cultura através da pesquisa - como nome de plantas, animais, lugares, mitologia, calendário lunar e ecológico, etc. - em um diálogo constante com os "velhos" da comunidade. Esses conhecimentos são acessados no âmbito das atividades de registro dos projetos, através dos aparelhos (técnicas e instrumentos) apreendidos nas oficinas de formação em pesquisa.

Durante o período que permaneci em São Gabriel, além de conviver pessoalmente com alguns desses jovens, conheci outros tantos que estavam de passagem pela cidade para receber bolsas ou participar de eventos promovidos pela FOIRN. Tive a oportunidade de vê-los circulando pelo centro da cidade e observá-los em reuniões, registrando tudo em seus cadernos de anotações. Ao retornar de barco para Manaus, fui premiado com a companhia de um desses jovens. Notei sua presença na embarcação devido a um fato curioso: logo no início da viagem (que durou dois dias), reparei que ele escrevia obstinadamente em um caderno, durante horas. Acabamos conversando bastante durante a viagem e, pouco antes dele desembarcar em Santa Isabel, perguntei o que escrevia no caderno. Após contar que era "pesquisador", o jovem explicou que estava treinando a prática do "registro escrito", anotando detalhes sobre as plantas e lugares encontrados na viagem. Ele mostrou algumas dessas anotações e pude notar o grau de detalhamento das informações e dos desenhos, algo que já havia visto antes nos cadernos de outros pesquisadores indígenas. Essa cena é boa para lembrarmos que a prática do registro e da observação já não é mais (se algum dia foi) uma exclusividade do antropólogo, muito menos dos cientistas brancos.

O mais importante é entender que os índios são sujeitos de agência nesse processo histórico, transformando os conhecimentos ao adquiri-los, convertendo os aparelhos e os objetos do branco, que passam a circular por outras redes. Mais antropofagia (enquanto antropologia) do que aculturação. Da mesma forma que os índios foram capazes de transformar o cristianismo em um instrumento poderoso de rebelião e resistência sociopolítica, conforme atestam os movimentos messiânicos que ocorreram no Noroeste Amazônico durante o século XIX (WRIGHT, 2005), parece certo que serão capazes de agenciar essas experiências de forma bastante criativa. As iniciativas no campo da educação diferenciada e intercultural, as demandas por constituição de uma "Universidade Indígena" na região e a luta das lideranças das associações pela conquista de maior autonomia política e econômica parecem apontar que a instituição da categoria de pesquisador indígena é apenas uma etapa em um processo histórico muito mais amplo. 


\section{Formas de Agenciamento Baniwa da Pesquisa}

Tendo como referência essas e outras trajetórias de pesquisadores baniwas e a minha própria convivência diária com eles durante o período em que permaneci em São Gabriel da Cachoeira, pretendo apresentar algumas reflexões sobre essa experiência etnográfica a partir de dois eixos temáticos: saber-fazer e domesticação da alteridade. Ambos estão inseridos no panorama mais amplo marcado pelo processo de "indigenização da modernidade" (SAHLINS, 1997). É importante notar que essas reflexões são ainda bastante iniciais e nada conclusivas, servindo mais como orientações para pesquisas futuras, pois exigem maior aprofundamento etnográfico. Por isso, fico satisfeito em apresentar resumidamente alguns pontos que acho importante levar em conta. A proposta é que essas questões possam servir de pano de fundo para o tópico final deste artigo, quando pretendo retomá-las a partir de um diálogo com a etnologia ameríndia.

\section{A Pesquisa Baniwa enquanto saber-fazer}

Os relatos dos pesquisadores baniwas sobre a experiência nos projetos dão ênfase ao aspecto mais "prático" do aprendizado. Ao invés de falar sobre o significado de conceitos como "agrobiodiversidade" ou "paisagens", eles mencionam o saber-fazer apreendido com os pesquisadores brancos: aplicação de questionários e entrevistas, elaboração de mapas, realização de trilhas para coleta ou identificação de plantas e lugares na mata; o uso do gravador, dos computadores, das máquinas fotográficas e do GPS; e as atividades de anotação e registro. Esses conhecimentos são adquiridos nas oficinas e expedições de coleta, através do exercício de habitação dos rios, das roças e da floresta na companhia dos pesquisadores brancos, o que implica ver as trilhas, plantas e lugares de outra perspectiva, através de outros aparelhos. Tratase do aprendizado de uma nova forma de percorrer o ambiente e de se movimentar pelas paisagens, a instauração de uma territorialidade baseada no mapeamento e no registro de um espaço estriado pelas técnicas cartográficas.

Existe uma materialidade prática desse aprendizado que envolve a tarefa de lidar com novos artefatos e colocá-los em ação em contextos específicos. Isso inclui aprender a manipular uma lista bastante extensa de instrumentos: câmeras de vídeo, gravadores, amostras, máquinas fotográficas, fitas métricas, mapas, GPS, microscópios e cadernos de anotações, entre outros. Isso envolve o domínio prático de um saber-fazer adquirido nas oficinas e nas atividades de campo, tendo como referência o uso que é feito desses objetos pelos pesquisadores.

Ao mesmo tempo, os baniwas mencionam as viagens realizadas na companhia dos colegas brancos, comentando com certo entusiasmo as experiências na universidade, nas instituições de pesquisa, nos eventos acadêmicos, nos almoços, nas reuniões e oficinas de trabalho. Nesses relatos, tecem observações sobre diferenças entre o mundo 
aldeão e o mundo do branco. Eles também observam como os brancos se comportam nesses lugares, a maneira como interagem entre si e os usos diversificados que fazem dos inúmeros objetos com os quais lidam diariamente, com ênfase na comparação entre suas diferentes disposições, habilidades e afecções. Afinal, conforme relatou um desses jovens: "branco não é tudo igual, reparando bem a gente nota que cada um é diferente do outro".

Nessas viagens para as grandes metrópoles, assim como nas expedições de coleta de dados, nas oficinas e reuniões realizadas em escritórios climatizados, são os brancos que se tornam objetos daquilo que Wagner (2010, p. 67) denominou de "antropologia reversa". Nesses momentos de convivência e experimentação, nós somos criteriosamente observados pelos índios enquanto objetos de curiosidade intelectual. No caso dos pesquisadores baniwas, essa antropologia reversa envolve aprender como é ser pesquisador no nosso mundo, o que implica a aquisição das habilidades e conhecimentos do branco. Esse processo de aprendizado não deve ser abordado como uma mera reprodução mecânica e mimética da nossa linguagem conceitual e corporal, pois envolve também a tradução de saberes. Essa tradução, no entanto, não é unicamente linguística, nem mesmo visa exclusivamente à descoberta ou revelação do sentido ou significado que os pesquisadores brancos dão aos seus aparelhos de pesquisa.

Vale notar que toda tradução envolve necessariamente certo grau de transformação e agência: "to translate is to connect, to displace, to move, to shift from one place, one modality, one form, to another while retaining something" (LAW, 2002, p. 99). Trata-se do aspecto "geométrico" da tradução, mencionado inicialmente nas reflexões de Serres (1974) e mais tarde retomado nos trabalhos de Callon (1980) e Latour (1987, p. 94). Toda tradução é feita a partir de determinada tradição (ou convenção), ao mesmo tempo em que envolve necessariamente certo grau de deslocamento de sentidos e invenção de novos usos e significados. Essa experimentação indígena com os conhecimentos do branco se dá a partir de um aprender a lidar que é também uma transformação dos aparelhos em instrumentos que possam servir aos seus interesses políticos.

Por último, gostaria de sugerir que para os baniwas esse aprender a lidar envolve necessariamente uma metamorfose corporal semelhante àquela vivenciada pelo pajé quando veste o corpo da onça: ao fornecer aos jovens que atuam nessas iniciativas novas capacidades e afecções, esses artefatos dão acesso a outros mundos possíveis. A cartografia permite visualizar e percorrer os lugares de uma maneira completamente diferente. Fazer uma trilha registrando o nome e marcando com plaquetas todas as árvores encontradas pelo caminho, coletando amostras e tirando fotos de animais e plantas, é diferente do que percorrer esses caminhos sem medi-los ou registrá-los. Vivenciar os lugares da roça e da floresta na companhia dos brancos e seus aparelhos permite experimentar novas formas possíveis de habitar esses espaços.

A pesquisa é entendida pelos pesquisadores baniwas como uma forma de experimentar o mundo dos brancos e, ao mesmo tempo, como 
uma maneira diferente de habitar o mundo indígena, de acessá-lo a partir da perspectiva fornecida pelos instrumentos tecnológicos usados pelos pesquisadores. Trata-se da pesquisa pensada a partir dos seus efeitos pragmáticos e ontológicos: o que interessa é a forma como esses novos instrumentos (o gravador, a máquina fotográfica, o GPS) permitem evocar outros mundos, através da produção de outros sinais perceptíveis. Mas esse aprendizado parece seguir mais a lógica da multiplicação de saberes do que da subtração ou substituição, em que adquirir novas habilidades e disposições não parece implicar o abandono de outras mais antigas. No lugar das nossas batalhas epistemológicas pela representação mais objetiva ou verdadeira de um mundo naturalista (monismo ontológico), os índios parecem optar pela multiplicação de saberes e ontologias (multiplicidade ontológica).

\section{A Pesquisa Baniwa enquanto Domesticação da Alteridade}

Os povos indígenas da região do Alto Rio Negro estão experimentando um período histórico marcado pela valorização dos conhecimentos tradicionais, apontados como "atalhos" em projetos de bioprospecção, modelos de manejo sustentável da floresta ou como patrimônio da humanidade (LITTLE, 2010, p. 16). Se até meados da década de 1980 os seus saberes eram abordados pelas agências de desenvolvimento como entraves à modernização ou como resquícios culturais que tinham que ser abandonados ou superados, atualmente desfrutam de uma visibilidade política significativa. Esses povos também não estão mais submetidos às ações nefastas de conversão étnica e religiosa dos missionários. Ao mesmo tempo, as fontes de financiamento de projetos na área de desenvolvimento sustentável e revitalização cultural se multiplicaram sensivelmente nas últimas décadas, atraindo grande quantia de recursos humanos e econômicos (ANDRELLO, 2006, p. 27).

Mas para desfrutar dos benefícios desse contexto histórico, esses povos precisam experimentar o mundo do branco, saber navegar por sua burocracia de forma a mobilizá-la em prol dos seus interesses. Para isso, é necessário saber lidar com os papéis e aparelhos administrativos e científicos de forma a transformá-los em instrumentos eficazes de resistência política. Isso envolve, em linhas gerais, elaborar e executar projetos e administrar associações políticas. Para isso, é preciso adquirir os saberes necessários para operar essas estruturas: escrever projetos, relatórios, orçamentos e, cada vez mais, fazer pesquisa. A aquisição desse conhecimento faz parte de um panorama mais amplo de relações históricas com agentes externos, envolvendo a experiência pregressa com os missionários e comerciantes, até as incursões mais recentes no mundo da escola e as expedições familiares em busca de trabalho. Conforme foi mencionado por Howard (2002), "sempre há espaço para driblar a dominação". Precisamos fazer um esforço para perceber as estratégias e táticas baniwas mobilizadas nesses diferentes contextos: "a apropriação cultural que as pessoas fazem de condições externas que 
elas não criam, e das quais não podem escapar, constitui o próprio princípio de sua ação histórica" (SAHLINS, 2004, p. 447).

Os pesquisadores baniwas - assim como as lideranças políticas, os professores e agentes de saúde indígena - estão na ponta extrema desse processo histórico. Ao transitarem entre o mundo aldeão e os escritórios climatizados dos aliados, esses atores enfrentam a difícil tarefa de lidar intimamente com o branco, seus conhecimentos e objetos. Nesses espaços interétnicos, eles agem como batedores avançados em um lento e contínuo processo de domesticação da alteridade, atuando ativamente na captura dos objetos e conhecimentos do branco e mediando a sua relação com as comunidades. Ao acompanhar e participar das expedições de coleta, esses jovens não só podem controlar melhor a ação dos pesquisadores, como também aprender a fazer pesquisa. Isso reflete, em parte, o interesse das lideranças em conquistar maior autonomia política através da produção de assessores indígenas, que tomariam o lugar dos brancos ou passariam a trabalhar ao lado deles. A proposta de formação de uma "Universidade Indígena" e o envio de jovens para fazer faculdade em universidades federais busca dar conta dessa demanda por formação de batedores que possam fazer o trabalho que, atualmente, é realizado em grande parte pelos assessores brancos.

Isso fica bastante evidente na forma como as lideranças agenciam o contexto mais amplo da regulamentação do acesso aos conhecimentos tradicionais, estabelecendo um campo de negociação que envolve a discussão dos objetivos e finalidades das pesquisas de forma a convertêlas em instrumentos de geração de benefícios para as comunidades. Com isso, pesquisadores precisam seguir uma série de procedimentos de negociação com as lideranças e comunidades, sendo convidados a colaborar com o projeto pedagógico das escolas, a realizar atividades "extracurriculares" ou ao menos explicitar seus objetivos previamente e deixar uma cópia do material escrito no acervo das associações. Esses esforços visam transformar os pesquisadores em aliados políticos que possam colaborar com a agenda do movimento indígena local.

Por outro lado, apesar dessas iniciativas serem orientadas em grande parte pela linguagem conceitual e metodológica dos brancos - de difícil entendimento por parte dos índios, principalmente aqueles que vivem nas comunidades - os resultados perceptíveis que elas geram em suas vidas podem ser avaliados de forma contínua. Apesar de nem sempre conseguir decifrar os sinais inscritos nas tabelas e gráficos dos pesquisadores, os índios podem avaliar se a quantidade de peixes no rio aumentou ou diminuiu; se as pragas que atacam as plantas da roça estão realmente desaparecendo; se o arumã usado na confecção do artesanato está aumentando ou não; se as pimentas fotografadas morreram. Essa percepção dos resultados práticos das pesquisas alimenta fofocas e boatos que passam a circular nas comunidades, outra forma muito eficiente de controlar a atuação das lideranças e seus parceiros brancos. Conforme relataram por diversas vezes os pesquisadores do ISA, as informações circulam rapidamente pelos rios da região. Eles contaram, por exemplo, como certos "desentendimentos" acabaram com a 
reputação tanto de projetos como também de pesquisadores, impedindo a continuidade de atividades.

Um evento recente ilustra muito bem essa questão. Há alguns anos, um pesquisador de uma universidade do sudeste brasileiro, biólogo, assessorou a FOIRN em um projeto na área de piscicultura. Com a intenção de monitorar a circulação dos cardumes nos rios, ele fez uso de uma espécie de "radar aquático": o aparelho era composto por um cabo longo que era introduzido no rio e gerava imagens que dificilmente poderiam ser confundidas com peixes, mas que chamaram grande atenção nas comunidades. Se num primeiro momento a atividade pareceu divertida e interessante, depois os baniwas começaram a se questionar se aquele instrumento, que permitia ver os peixes embaixo d'água, não estimularia à ira desses seres aquáticos, levando-os a projetar doenças sobre as comunidades. Em poucos meses, boa parte dos índios da região já estava informada sobre $o$ estranho evento envolvendo 0 tal pesquisador, seu radar e o mundo dos peixes. Quando o pesquisador tentou fazer uso do aparelho novamente, foi advertido pelos seus colegas indígenas a guardá-lo imediatamente. Esse evento também ilustra que a apropriação dos artefatos tecnológicos do branco envolve a seleção do que deve ou não ser incorporado: uma "economia da alteridade" enquanto modo de predação e subjetivação (VIVEIROS DE CASTRO, 2002, p. 26794).

A indigenização do socioambientalismo também ocorre a partir de uma série de microestratégias usadas no dia a dia das organizações indígenas e que envolvem usos alternativos e informais dos recursos disponibilizados através dos projetos, como o aproveitamento da estrutura física (barcos, motores, gasolina, mantimentos etc.) para finalidades não previstas nos cronogramas e as pequenas táticas de envolvimento dos parentes em atividades realizadas no âmbito dos projetos. Apesar dos mecanismos de fiscalização e mapeamento do uso dos recursos por parte dos órgãos financiadores, sempre há certa margem de manobra, por menor que seja. As lideranças das associações não só estão aprendendo a lidar com a burocracia do branco, mas também estão experimentando formas de driblar os mecanismos de controle externo, agenciando táticas que orientam usos alternativos das estruturas administrativas.

$O$ resultado desse trabalho é inquestionável. Ao longo das últimas décadas, a FOIRN constituiu uma rede de transporte e comunicação que fortaleceu a sua atuação nas comunidades do interior: atualmente essa associação conta com mais de 80 embarcações motorizadas e uma centena de terminais radiofônicos localizados nas comunidades do interior. Essa estrutura foi adquirida, em grande parte, com os recursos dos projetos de desenvolvimento sustentável e vem sendo utilizada para finalidades mais amplas do que as atividades previstas nos cronogramas. A possibilidade de manter uma comunicação constante com as centenas de comunidades localizadas nos inúmeros rios e igarapés da região é um dos fatores que fazem dessa organização indígena uma das mais fortes no cenário nacional. Ao que parece estamos diante de uma situação em 
que o "desenvolvimento sustentável" é agenciado e transformado em "desenvolvi-gente" (SAHLINS, 2004, p. 450).

Este parece ser o caso do uso que os índios fazem das bolsas, diárias e outras formas de pagamento de serviços prestados no âmbito dos projetos. Esses recursos dificilmente são acumulados, mas passam automaticamente a circular entre os parentes mais próximos. Acompanhei esse fenômeno no caso dos pesquisadores baniwas. L. S. repassava suas diárias diretamente para a esposa, que usava o dinheiro para comprar roupas e comidas, que eram automaticamente distribuídos entre os filhos e parentes mais próximos. M. S., por exemplo, negociava com a mulher os períodos de ausência de casa com roupas e mercadorias adquiridas com a bolsa de pesquisador. Também notei por diversas vezes que ele era alvo constante de parentes que estavam de passagem pela cidade e pediam pequenas contribuições para almoçar ou comprar roupas, gasolina e utensílios domésticos. A. B., por sua vez, apesar de permanecer boa parte do tempo na sede da associação, em São Gabriel da Cachoeira, fazia questão de manter casa e roça na sua comunidade de origem, fazendo uso dos recursos acessados nos projetos para beneficiar seus parentes.

Existem, no entanto, alguns riscos associados à função de batedor desempenhada pelos pesquisadores e lideranças baniwas: o perigo de não conseguir administrar as demandas colocadas pelos parentes. Como o restante da comunidade nem sempre detém um entendimento dos procedimentos burocráticos associados à administração de projetos, os líderes e pesquisadores podem ser facilmente acusados de estar sendo sovina, uma característica considerada extremamente negativa para uma liderança. Acompanhamos anteriormente os dilemas enfrentados por $\mathrm{M}$. S. na administração da associação comunitária e durante o período que permaneci na região ouvi diversos relatos que retratavam situações semelhantes.

Por outro lado, o fato dos pesquisadores baniwas andarem mais na companhia dos parceiros brancos, comerem a sua comida, frequentarem seus eventos e usarem suas tecnologias (que lhes dá acesso à outra perspectiva-mundo), é entendido como uma atividade arriscada que, se não for conduzida com sabedoria, poderá levá-los a uma metamorfose sem retorno. Por isso, é importante tomar certos cuidados, como evitar trocar a comida indígena pela comida do branco, valorizar o saber-fazer comunitário (as festas, danças e o trabalho na roça), manter um comportamento adequado para não se tornar uma vítima em potencial de feitiçaria, continuar falando a língua e valorizando as relações com os parentes. Quando isso não ocorre, esses batedores avançados nesse processo histórico de domesticação da alteridade correm o sério risco de virar branco ou ser alvo de feitiços.

\section{Os Conhecimentos e as Mercadorias do Branco nas Ontologias Indígenas do Alto Rio Negro: alteridade, risco e domesticação}

O fascínio indígena por tecnologias, conhecimentos e mercadorias ocidentais faz parte da história do contato entre brancos e povos 
indígenas no Alto Rio Negro e, de uma maneira geral, de toda a América do Sul. O fato é que os indígenas da região - desde os primórdios do contato - estão lutando para ter acesso às tecnologias geradas pelo sistema capitalista. Nesse processo, certos objetos são extremamente valorizados: motores de polpa, geradores elétricos, utensílios domésticos, roupas, produtos de higiene pessoal, celulares, televisores, rádios, antenas parabólicas e máquinas fotográficas. Basta transitar pelo centro de São Gabriel para ver grupos de índios - muitos deles provenientes das comunidades do interior - circulando pelas lojas do comércio local, admirando e adquirindo essas mercadorias. Esse desejo por objetos ocidentais foi comumente citado como um exemplo de que eles estariam passando por um processo de "aculturação" marcado pela incorporação do estilo de vida ocidental a partir da assimilação das mercadorias e, através delas, do próprio capitalismo. Segundo essa perspectiva, os índios são representados como vítimas passivas da história, submetidos à superioridade tecnológica ocidental.

A literatura etnológica que será usada como referência surge como uma crítica a essa perspectiva da "aculturação", tendo como ponto de partida o estudo clássico de Sahlins $(2003,2004)$ sobre as "cosmologias do capitalismo". Nesse estudo, o autor dá ênfase à agência indígena no processo de assimilação das mercadorias ocidentais, buscando ver como "os produtos e até as pessoas do Ocidente foram incorporados como potências nativas" (Idem 2004: 448), argumentando que essa incorporação se dá mediada por "esquemas culturais locais". Os três exemplos etnográficos apresentados por Sahlins nesse artigo ilustram formas diferentes de integração das mercadorias ocidentais nos sistemas culturais nativos, dando ênfase à agência indígena.

A mesma ideia de agenciamento indígena dos conhecimentos e mercadorias do branco orientou a concepção de três coletâneas importantes. A primeira foi organizada por Appadurai (1986) e tem como ponto fundamental a noção de que os objetos possuem uma história de vida, podendo transitar entre a condição de "mercadoria" e outras condições definidas pelos regimes de valor locais, com ênfase na forma como são concebidos e transformados na medida em que circulam em contextos culturais específicos. Os artigos reunidos nessa coletânea abordam a relação existente entre conhecimento e mercadoria, tanto no que se refere à sua produção, mas, principalmente, no que se refere ao consumo desses objetos, com ênfase na forma como as mercadorias são apropriadas e inseridas nas redes locais e regionais. Ao iluminar o caráter transformativo da aquisição de mercadorias por povos não ocidentais, esses estudos apontam para a criatividade e a agência que acompanha a apropriação desses objetos exógenos em contextos socioculturais específicos.

Esse tema é retomado no livro organizado por Stephen Hugh-Jones e Caroline Humphrey (1992), onde os autores argumentam que é preciso entender a forma como objetos exógenos (como as mercadorias ocidentais) são concebidos e integrados, enquanto novidades, em regimes de valor autônomos e relativamente independentes do sistema de valor do fornecedor. Essa perspectiva é desenvolvida por S. Hugh-Jones 
(1992) em um estudo centrado no contexto do Alto Rio Negro, onde esse autor aborda o fascínio dos índios pelas mercadorias ocidentais, demonstrando claramente que a economia indígena possui uma lógica própria e que os índios não são vítimas nesse processo, pois a apropriação de mercadorias e sua integração nas redes locais são processos correlatos que envolvem certo grau de agência. Outros autores dessa coletânea buscam pensar a forma como as mercadorias ocidentais são inseridas e apropriadas em regimes de escambo locais, como os artigos de Strathern (1992) e de Gell (1992), ambos realizados no contexto Melanésio. Todos esses autores apontam a agência indígena que acompanha a apropriação desses objetos em contextos socioculturais específicos.

Na coletânea organizada por Bruce Albert e Alcida Ramos (2002), os autores buscam investigar os dispositivos nativos de domesticação simbólica e ritual da alteridade representada na figura do branco, incluindo a captura sócio-simbólica dos bens ocidentais, que "requalifica esses bens exóticos, que podem até ser fisicamente 'reprocessados', muito além do eventual valor de uso que lhes é atribuído. Assim, redefinidos e incorporados a título de símbolos de exterioridade capazes de conferir prestígio local, eles são postos em circulação a serviço do dinamismo social indígena" (ALBERT e RAMOS, 2002, p. 12).

Essa perspectiva é desenvolvida por outros autores da coletânea a partir de estudos realizados entre diferentes coletivos indígenas da região noroeste da Amazônia. O trabalho de Howard (2002) entre os Waiwai demonstra claramente como os objetos associados à figura do branco são socializados na medida em que são "processados pela trama social". O estudo de Velthem (2002) entre os Wayana mostra como as mercadorias do branco são retrabalhadas e modificadas através de intervenções estéticas e, principalmente, no uso que é dado a elas. O artigo de Gallois (2002) mostra como os índios Waiãpi do Amapari consideram que "as máquinas, o ouro, a escrita etc., são técnicas e saberes inventados pelo herói criador Janejar no tempo das origens e os Waiãpi pretendem agora recuperar" (Ibidem, p. 230).

Os gravadores, aparelhos de GPS, mapas, computadores, softwares, questionários, filmadoras, máquinas fotográficas, livros, além das técnicas associadas ao seu uso, integram o rol de mercadorias ou objetos introduzidos pelo branco no Alto Rio Negro, o que permite inferir que estão expostos às mesmas práticas de agenciamento e transformação. Para entender melhor a relação dos índios dessa região com esses aparelhos, temos que olhar antes para a forma como a figura do "branco" é retratada em sua mitologia.

Entre os Barasana, povo tukano da região do Uaupés, os brancos são mencionados em um único ciclo mitológico (HUGH-JONES, 1988), associado ao herói cultural Wãribi ("ele-que-foi-embora"), muitas vezes identificado com a figura do "Cristo" ou com o próprio deus cristão. Foi Wãribi que ensinou ao ancestral dos brancos o conhecimento necessário para a fabricação de todos os objetos manufaturados, enviando-o em direção ao leste para que não criasse confusão. Com isso, o branco é associado na mitologia tanto ao herói cultural Wãribi (identificado com o 
seu componente religioso), quanto à figura da onça, associada aos representantes mais violentos do mundo do branco, como os policiais e militares (Ibidem, p. 143).

Esse tema é retomado na narrativa mitológica sobre a origem dos seres humanos, onde o ancestral dos brancos é retratado como o irmão mais novo (HUGH-JONES, 1988, p. 144). Nesse mito, o caráter destemido dos brancos é representado pelo fato deles terem se lavado primeiro, razão pela qual seus corpos são claros em contraposição a cor mais escura dos índios. Em outro trecho do mesmo mito, quando o herói cultural thes oferece a possibilidade de escolher entre um conjunto de artefatos, os índios, por serem mais velhos, escolhem primeiro e optam pelo arco e pelos ornamentos rituais, enquanto o branco fica com a arma de fogo. Como os brancos passam a ameaçar os outros povos com suas armas, eles acabam sendo expulsos por Wãribi em direção ao leste. Esse mito ilustra três elementos de alteridade associados à figura do branco: a forma estética dos corpos; a origem das armas; e o comportamento bélico. Segundo Hugh-Jones (1988, p. 146), a diferença entre as armas de fogo e os arcos e ornamentos rituais reflete uma diferença de caráter e estilo de vida, contrastando o comportamento agressivo e descontrolado do branco com a tranquilidade, o controle reflexivo e o comportamento ritualizado dos índios.

Esse tema também foi pesquisado por Wright (2000) entre os Baniwa que vivem na região do Içana. Segundo esse autor, na mitologia desse povo os brancos (ialanawi) são associados ao mundo das divindades (WRIGHT, 2000, p. 432). O herói cultural Kuwai - filho do criador supremo Nhãperikuli (que deu origem ao mundo espiritual) ensinou a humanidade os primeiros ritos de iniciação e o saber (ianheke) para que os homens continuassem o processo. Foi das cinzas do seu corpo que nasceu a palmeira de onde são feitas as flautas sagradas usadas nos rituais de iniciação masculina. Ele é retratado no mito vestindo sapatos e usando relógios e sua mãe, Amaru, é considerada a "mãe dos brancos" (históricos).

Desta forma, tanto entre os Barasana como entre os Baniwa, os brancos foram associados ao mundo dos ancestrais e a origem primordial de seus conhecimentos e mercadorias está retratada na mitologia, havendo uma relação entre os conhecimentos tecnológicos do branco e os conhecimentos xamânicos, ambos repassados aos humanos por heróis míticos. Assim, tanto Wright como S. Hugh-Jones parecem admitir a possibilidade de retomada desses conhecimentos pelos índios como algo presente no próprio discurso mítico: no caso dos Barasana, o mito de Wãribi descreve os conhecimentos do branco como uma transformação dos conhecimentos xamânicos, deixando em aberto a possibilidade dos pajés contemporâneos recuperarem esse conhecimento (HUGH-JONES, 1988, p. 150); no caso dos Baniwa, a interpretação messiânica do mito de Kuwai também parece sugerir uma possibilidade de apropriação desses conhecimentos ao profetizar uma transformação dos índios em brancos e vice-versa (WRIGHT, 2000, p. 431).

Esse tema é retomado em etnografias realizadas na região por Lasmar (2005) e Andrello (2006) sobre índios vivendo no contexto 
urbano. Essas etnografias dão atenção especial para a forma como os índios citadinos pensam a relação com o branco, seus objetos e conhecimentos. Lasmar (2005) menciona a existência de uma aproximação conceitual entre a figura do branco e os Wa'ïmasa ("seres do fundo do rio" ou "Gente-Peixe"), pois ambos seriam portadores de um uuró ("falar"/"emitir som") intenso. No caso do branco, essa potência é expressa através da sua riqueza e poder, qualidades associadas à capacidade transformativa das mercadorias e conhecimentos, em que "apropriar-se do conhecimento dos brancos é adquirir suas potências criativas, algo que se torna possível principalmente por meio da escola" (LASMAR, 2005, p. 236).

Lasmar cita como exemplo o envolvimento dos povos indígenas do Alto Rio Negro com o "projeto civilizatório" dos missionários salesianos que, apesar de combaterem diretamente instituições essenciais para $o$ seu modo de vida (como 0 xamanismo), disponibilizavam aos alunos oficinas de capacitação em costura e carpintaria, além das atividades de alfabetização e escrita (2005, p. 241). Andrello também menciona como exemplo o engajamento dos índios de lauareté no projeto educacional dos missionários salesianos, buscando demonstrar como esse envolvimento possibilitou-Ihes um agenciamento (através da personificação) de conhecimentos e capacidades do branco (ANDRELLO, 2006, p. 330-41). Essa questão também é abordada por Luciano Santos (2006, p. 86-87), que aponta a importância da formação escolar adquirida nas escolas dos missionários na trajetória das lideranças que atuaram na formação das organizações indígenas e nos debates em torno da demarcação de suas terras.

Andrello também aponta a existência de "um projeto indígena de conquista das fontes de poder e conhecimento situadas rio abaixo, para então, sob controle, colocá-lo em operação no cotidiano de lauareté”, pois os "recursos e saberes controlados por agentes externos eram disputados por atores locais" devido ao seu poder de transformação da realidade (ANDRELLO, 2006, p. 51). Esse autor menciona o uso da categoria pekâsãyee pelos índios da região, que significa "fazer-se branco", movimento semelhante ao devir-branco mencionado por Lasmar (2005, p. 256-257). Ele também cita a associação feita pelos índios entre a figura do branco e os wa'ïmasa, considerados "inimigos" em potencial devido à relação de predação que mantêm com os humanos.

Após destacar o estatuto primordial da predação nas ontologias ameríndias, Andrello propõem pensar essa questão tendo como referência o contexto etnológico do Alto Rio Negro, onde os bens e conhecimentos são adquiridos dos ancestrais (ANDRELLO, 2006, p. 6365). As mercadorias tão valorizadas entre os índios da região são "objetos de branco" cuja posse investe seu proprietário de respeito e prestígio, assim como o dinheiro (kumu-papéra), ambos associados à aquisição de novas capacidades (Ibidem, p. 246-258). Andrello sugere que a obtenção dessas coisas do branco se insere no mesmo registro que a obtenção de objetos de outros grupos (afins), pois os artefatos especializados (por exemplo, raladores baniwa) são denominados de apeka (outras-coisas), sendo que o mesmo termo é usado para se referir as coisas do branco 
(apeka de branco). Andrello sugere que fazer-se branco (pekâsã-yee), neste contexto, implicaria uma "encorporação" dos conhecimentos e mercadorias ocidentais, entendidas como atributos e capacidades do branco (ANDRELLO, 2006, p. 409).

Essa parece ser a lógica que orienta a concepção da pesquisa enquanto a apreensão de um saber-fazer específico relacionado às disposições corporais dos pesquisadores, reproduzidas através de uma capacitação/transformação do próprio corpo. É por isso que L. S. costumava contar que, quando andava na companhia dos pesquisadores brancos, "vestia" o corpo de pesquisador. Talvez seja por isso que em todos os nossos encontros, ele sempre foi vestido com suas melhores roupas de branco (camisa, calça, relógio e sapatos), carregando consigo cadernos, livros e canetas, mesmo quando o seu uso não era necessário. Essa era a forma de se "converter" em um pesquisador: apesar do desconhecimento sobre os detalhes teóricos e conceituais do projeto sobre paisagens, ele reproduzia um devir-pesquisador marcado pela incorporação das suas disposições corporais, apreendidas enquanto a expressão de capacidades ou atributos.

O uso de gravadores, máquinas fotográficas e filmadoras para registrar a vida cerimonial da comunidade, assim como as experiências de transcrição dos mitos, as atividades de "coleta" de plantas e animais na mata, o uso de microscópios, telescópios, computadores, mapas e outros artefatos tecnológicos associados ao mundo da pesquisa, representa uma conjuntura histórica bastante paradigmática para os povos indígenas do ARN. Os jovens indígenas que acompanham os pesquisadores estão na vanguarda de um processo mais amplo de apropriação dessas tecnologias, transformando seus próprios corpos ao vestir os "adornos" de seus colegas. A apropriação dessas técnicas e desses instrumentos de pesquisa - e os seus respectivos atributos e capacidades - envolve inúmeras traduções, muita negociação e provavelmente certo desentendimento.

Garnelo cita os trabalhos de Wright (1981) e Journet (1995) para se referir à atividade guerreira entre os baniwa, entendida como modelo nativo para pensar a relação com a alteridade, no qual "jovens combatentes são momentaneamente autorizados a transpassar as fronteiras da sociedade, (...) para encetar a obtenção de bens simbólicos que potencializam as possibilidades de reprodução da sociedade" (GARNELO, 2003, p. 119 ). Essa autora menciona a emergência do "branco" e seu enquadramento como um caso particular de alteridade radical, "expresso por sua inserção no panteão de seres mais agressivos e perigosos do imaginário baniwa" (Ibidem). Surge daí a "necessidade de mediadores especializados no contato interétnico, cuja missão visa à transposição das fronteiras étnicas em busca dos saberes/poderes dos brancos" (Ibidem), sendo que os exemplos de "mediadores" citados pela autora incluem as lideranças indígenas, os agentes de saúde e os professores. Garnelo também menciona o perigo e o risco associado ao exercício dessa mediação voltada para a domesticação do branco e seus conhecimentos (eleito como modelo de alteridade radical), sendo que a condição liminar dos mediadores indígenas pode torná-los objetos de 
temor e vigilância (GARNELO, 2003, p. 122), motivo pelo qual evitam uma diferenciação do modo de viver baniwa para não despertar a inveja das pessoas, o que os deixaria vulnerável às ações de feitiçaria (Ibidem, p. 99).

O uso da noção de mediação para descrever o papel desempenhado pelos pesquisadores indígenas nesses projetos de pesquisa merece algumas observações importantes. A primeira é que essa noção também foi usada pelos pesquisadores brancos para definir seus colegas indígenas como meios de comunicação (e tradução) entre a comunidade e a equipe do projeto. Essa ideia, quando usada pelos pesquisadores brancos, está relacionada ao pressuposto ontológico da interculturalidade como um diálogo entre culturas, que tem na figura do pesquisador nativo a sua expressão mais evidente. Em certo sentido, quando os pesquisadores brancos se referem aos pesquisadores indígenas como "interlocutores", eles estão fazendo isso a partir de um paradigma próprio das grandes metrópoles contemporâneas: o trânsito realizado por indivíduos que possuem a capacidade de lidar com vários códigos culturais e desempenhar diferentes papéis sociais. Ao fazer isso, dão ênfase à ação de deslocamento dos pesquisadores indígenas entre duas culturas - a do branco e a do índio - concebendo a "capacitação" como a "formação intelectual" que fornece os meios para que esse trânsito seja realizado com sucesso, sem desconsiderar o risco de "aculturação" associado ao desempenho desse papel. É exatamente o pressuposto de que o pesquisador indígena se apropria dos instrumentos e da linguagem, necessários para realizar esse trânsito, que reforça a noção correlata da "tradução" enquanto uma atividade de mão-dupla (do projeto para a comunidade e vice-versa).

As etnografias de Lasmar (2005) e Andrello (2006) sugerem que o movimento de aquisição dos conhecimentos e mercadorias do branco deve ser pensado tendo como referência a centralidade da corporalidade nas práticas de conhecimento e ontologias ameríndias (SEEGER, DAMATTA e VIVEIROS DE CASTRO, 1976). Desta forma, assim como o pajé precisa vestir o corpo da onça para acessar o mundo deste animal e apreender os seus conhecimentos/poderes, o pesquisador baniwa percebe toda mediação da alteridade como um processo de metamorfose corporal. Conforme essa lógica, a aquisição de conhecimentos provenientes do mundo do branco implica necessariamente em uma transformação corporal, pois toda forma de conhecimento é sempre uma personificação de atributos e capacidades. Com isso, apesar dos pesquisadores e lideranças baniwas concordarem com a noção de "trânsito", este é definido como um deslocamento entre naturezasculturas a partir da aquisição de novas habilidades, disposições e afecções.

O devir-pesquisador dos baniwa envolve a acoplagem dos equipamentos do branco (técnicas e instrumentos), que passam a compor um novo corpo, permitindo capturar os elementos que constituem essa alteridade, domesticando-a como meio de revelação - enquanto evocação ontológica - de outro mundo. Isso envolve tanto ver as trilhas, roças e a própria cultura a partir da perspectiva dos brancos, como também colocar 
esses aparelhos a favor do fortalecimento da vida comunitária. Se os pesquisadores do ISA percebem essas iniciativas como uma relação entre culturas, os índios parecem vivenciá-la enquanto encontro de ontologiasmundos. No lugar de conceber a formação em técnicas de pesquisa enquanto "mudança cultural", os índios entendem a experimentação com os artefatos tecnológicos (gravadores, GPS, etc.) como uma metamorfose corporal, um devir-equipamento que lhes permite acessar outro mundo da mesma forma que o corpo-onça do pajé lhe permite experimentar o universo dos espíritos da floresta, onde os animais vivem como humanos.

Segundo Viveiros de Castro (2015), o perspectivismo e o multinaturalismo ameríndios constituem um universo de multiplicidade ontológica onde impera uma "metafísica da predação" que tem no canibalismo a sua expressão mais concreta. Partindo de uma reflexão sobre o "canibalismo póstumo" dos Araweté e o canibalismo tupinambá, Viveiros de Castro aponta para a existência de uma "economia da alteridade predatória" como eixo central da socialidade amazônica: a identidade está subordinada à diferença (Ibidem, p. 159-160). Ou seria melhor dizer que a Identidade não existe, pois estamos diante de um contínuo processo de diferenciação que não reconhece eixo central de referência e que tem como fonte primordial a alteridade. Os pesquisadores baniwas parecem exercer a função de predação da alteridade expressa no habitus dos pesquisadores brancos, seguindo uma lógica muito presente nas cosmologias ameríndias, em que "o 'eu' se determina como "outro'" e o corpo social é continuamente inventado e reinventado a partir da apropriação-tradução de recursos simbólicos vindos do exterior, seja dos aliados, dos afins, dos inimigos ou dos mortos.

O engajamento dos baniwas em pesquisas - e a consequente instituição da categoria de "pesquisador indígena" no âmbito de iniciativas socioambientais - integra um movimento mais amplo de domesticação do branco, marcado pela apreensão perspectiva dos seus saberes e objetos. Transformar-se em "pesquisador" - processo de metamorfose corporal - resulta na possibilita de assumir o ponto de vista do "Outro" sobre si mesmo, alternando perspectivas e, com isso, fornecendo novos subsídios para o contínuo processo de "invenção da cultura", no sentido que Wagner (2010) dá a esse termo.

A diferença é como uma Garrafa de Klein, na qual o interior está aberto ao exterior, onde não existe interior/exterior, mas apenas a borda que constantemente transborda, fazendo rizoma a partir das raízes mais duras. Os pesquisadores baniwas são como batedores avançados em uma guerra (conduzida com diplomacia) visando o controle e a domesticação dos brancos, materializada no exercício de apropriação de suas tecnologias e saberes. Toda tradução é também uma transformação. Todo "diálogo" é, em última instância, uma estratégia de apropriação simbólica dos elementos que compõem a alteridade. A mediação ameríndia é pura metamorfose corporal e transmutação de perspectivas. 


\section{Referências Bibliográficas}

ALBERT, B.; RAMOS, A. (Org.). Pacificando o branco: cosmologias do contato no norte-amazônico. São Paulo: Editora UNESP, 2002.

APPADURAI, A. (Edit.). The Social Life of Things: commodities in cultural perspective. Cambridge: Cambridge University Press, 1986.

ANDRELLO, G. Cidade do Índio: transformações e cotidiano em Iauaretê. São Paulo: Editora UNESP/ISA, 2006.

CALLON, Ml. Struggles and negotiations to define what is problematic and what is not: the sociology of translation. In: KNORR CETINA, K.; WHITLEY, R.; KROHN, R. (Eds.). The Social Process of scientific investigation: sociology of the Sciences Yearbook. Dordrecht e Boston: Reidel, 1980.

GALLOIS, D. T.. "Nossas falas duras": discurso político e auto-representação Waiãpi. In: ALBERT, B. e RAMOS, A. (Org.). Pacificando o branco: cosmologias do contato no norte-amazônico. São Paulo: Editora UNESP, 2002.

GARNELO, Luísa. Poder, hierarquia e reciprocidade: saúde e harmonia entre os Baniwa do Alto Rio Negro. Rio de Janeiro: Editora Fiocruz, 2003.

GELL, A. Inter-tribal commodity barter and reproductive gift-exchange in old Melanesia. In: HUMPHREY, C. e HUGH-JONES, S. (Org.). Barter, Exchange and Value: an anthropological approach. Cambridge, New York: Cambridge University Press, 1992.

HOWARD, C. A domesticação das mercadorias: Estratégias Waiwai. In: ALBERT, Bruce e RAMOS, Alcida (Org.). Pacificando o branco: cosmologias do contato no norte-amazônico. São Paulo: Editora UNESP, 2002.

HUGH-JONES, S. Yesterday's luxuries, tomorrow's necessities: business and barter in northwest Amazonia. In: HUMPHREY, C. e HUGH-JONES, S. (Org.). Barter, Exchange and Value: an anthropological approach. Cambridge, New York: Cambridge University Press, 1992.

HUGH-JONES, S. The Gun and the Bow: myths of white men and Indians. L'homme, Paris, Vol. 28, N. 106-107, p. 138-155, 1988.

HUMPHREY, C. Fair dealing, just rewards: the ethics of barter in North-East Nepal. In: HUMPHREY, C. e HUGH-JONES, S. (Org.). Barter, Exchange and Value: an anthropological approach. Cambridge, New York: Cambridge University Press, 1992.

JOURNET, N. La paix des jardins: structures socials des indiens curipaco do haut Rio Negro (Colombia). Paris: Musée de L’Homme/CNRS, 1995.

LASMAR, C. De volta ao Lago de Leite: gênero e transformação no Alto Rio Negro. São Paulo: Editora UNESP/ISA, 2005. 
LATOUR, B. Ciência em Ação: como seguir cientistas e engenheiros sociedade afora. São Paulo: Editora UNESP, 1987.

LAW, J. Aircraft Stories: decentering the object in technoscience. Durham and London: Duke University Press, 2002.

LITTLE, P. E. (Org.). Conhecimentos Tradicionais para o século XXI: etnografias da intercientificidade. São Paulo: Editora Annablume, 2010.

LUCIANO, G. J. S. "Projeto é como branco trabalha, as lideranças que se virem para aprender e nos ensinar": experiências dos povos indígenas do Alto Rio Negro. $162 \mathrm{f}$. 2006. Dissertação (Mestrado em Antropologia Social) - PPGAS, UNB, Brasília, DF, 2006.

SAHLINS, M. Cosmologias do Capitalismo: o setor transpacífico do "sistema mundial". In: SAHLILNS, M. Cultura na prática. Rio de Janeiro: Editora UFRJ, 2004.

Cultura e Razão Prática. Rio de Janeiro: Jorge Zahar, 2003.

SEEGER, A.; MATTA, R.; VIVEIROS DE CASTRO, E. A Construção da Pessoa nas sociedades indígenas brasileiras. Boletim do Museu Nacional, Série Antropologia, N. 32, p. 2-19, 1979.

SERRES, M. Hermes III: la traduction. Paris: Les Éditions de Minuit, 1974.

STRATHERN, M. Qualified value: the perspective of gift Exchange. In: HUMPHREY, Caroline e HUGH-JONES, Stephen (Org.). Barter, Exchange and Value: an anthropological approach. Cambridge, New York: Cambridge University Press, 1992.

VELTHEM, L. H. "Feito por inimigos": os brancos e seus bens nas representações Wayana do contato. In: ALBERT, B. e RAMOS, A. (Org.). Pacificando o branco: cosmologias do contato no norte-amazônico. São Paulo: Editora UNESP, 2002.

VIVEIROS DE CASTRO, E. A inconstância da alma selvagem. São Paulo: Cosac Naify, 2002.

Metafísicas Canibais: elementos para uma antropologia pós-estrutural. São Paulo: Cosac Naify, 2015.

WAGNER, R. A Invenção da Cultura. Rio de Janeiro: CosacNaify, 2010.

WRIGHT, R. História Indígena e do Indigenismo no Alto Rio Negro. São Paulo: Mercado das Letras / Editora do ISA, 2005.

. IaIanawinai: o branco na história e mito Baniwa. In: ALBERT, Bruce e RAMOS, Alcida (Org.). Pacificando o branco: cosmologias do contato no norte-amazônico. São Paulo: Editora UNESP, 2002.

History and Religion of the Baniwa peoples of Upper Rio Negro Valley. 630 f. 1981. Tese (Doutorado em Antropologia) - Department of Anthropology, Stanford University, California, 1981. 
Espaço Ameríndio

Recebido em: 24/10/2018* Aprovado em: 23/06/2019* Publicado em: 30/12/2019 